doi: $10.26529 /$ cepsj.545

\title{
Editorial
}

\section{Exploring Processes in Constructing Mathematical Concepts and Reasoning through Linking Representations}

The idea of representation is continuous with mathematics itself. Any mathematical concept must be represented in some way if it is to be present in the learner's mind. We distinguish between external representation (environment) and internal representation (mind). External representation refers to all external media that have as their objective the representation of a certain mathematical idea. We mainly use the term external representation for tangible material, graphical representation and mathematical symbols. External representation always needs an interpreter, a learner who gives it meaning.

The fact is that teaching and learning mathematics is more effective in terms of understanding mathematical ideas if it focuses on investigating different representations of a particular mathematical concept and encourages pupils to find links between these representations. Representations are predicated neither in terms of the adequacy of the relationship between ideas and their representations, nor as heuristic devices in meaning-making processes; they are rather an integral part of the activity of knowledge presentation. Representing mathematical ideas has the following main roles in the process of teaching and learning: interpretation of what is represented (internal presentations), recording, representing ideas (ways of thinking, knowledge presentation externally), and communicating (e.g., discussion about representations). The last two roles are the focus of this focus issue of the CEPS Journal: we aim to bring together different issues concerning representing learners' ways of thinking, knowledge presentation, and the role of external representations in the process of teaching and learning mathematics. On the one hand, we are interested in how students explain and share their ways of thinking in order to better understand their progress in learning; on the other, we would like to rethink the role of external representations. Stated more generally, our concern is how knowledge presentations can help the learner to develop competences; not only mathematical competences, but also those that empower her/him to make well-grounded decisions and use mathematics in ways that fulfil her/his needs as a constructive and thoughtful person. In this focus issue of the CEPS Journal, we contribute to the area of research on representations of mathematical ideas with four contributions. Each of them deals with a specific issue regarding the topic, while also covering different age groups of students, from preschool children to primary teacher students. 
The first paper, Engaging Young Children with Mathematical Activities Involving Different Representations: Triangles, Patterns, and Counting Objects by Dina Tirosh, Pessia Tsamir, Ruthi Barkai and Esther Levenson, deals with the idea of how young learners in preschool education interpret, construct or complement different external representations with regard to counting, triangles and patterns. In the first study (counting), the different representations complemented each other by offering children different information, such as where to begin and where to end the counting process. When a group of preschool children were asked to identify triangles, most them paid more attention to visual information than to the critical attributes of a triangle. In the children's investigation of patterns, concrete and tablet representations complemented each other by containing different information. The basic idea that the authors wanted to bring to the area of research on representations with these issues was not comparing the difference between concrete and figural representations in the same context, but showing that even when using the same physical materials, representations can be varied to support children's learning, meaning that even similar types of representations can afford young children different opportunities to engage with mathematical learning.

The second paper, Drawings as External Representations of Children's Fundamental Ideas and the Emotional Atmosphere in Geometry Lessons by Dubravka Glasnović Gracin and Ana Kuzle, focuses on primary school students' graphical representations of basic ideas in geometry and their experience of the teaching and learning of geometry, which, in the contribution, is considered as the emotional atmosphere in lessons. The theoretical framework related to the emotional atmosphere in a classroom was used to investigate the classroom climate. This framework can be regarded from a psychological and a social point of view. The psychological dimension refers to the level of the individual and involves affective conditions and affective properties, while the social dimension refers to the classroom community. The multiple case study results show that the four primary grade students presented a rather narrow conception of geometry, mostly depicting the fundamental idea of geometric forms and their construction, while the analysis of the emotional atmosphere in geometry lessons on the level of the individual could, on the basis of the four cases, be described as positive, unidentifiable or ambivalent, but certainly not dominantly negative. In the article, we encounter a rather new idea of using representations not only for interpreting student knowledge, but also for other, similarly important issues in the classroom; specifically, the emotional atmosphere. The students' drawings tell us how they experience the atmosphere in the classroom, which is closely connected to the basic ideas they represented (from their drawing, there 
are no examples of problem solving, orientation in space, geometry in everyday life, etc.). From their research, the authors draw some practical and theoretical implications for the teaching and learning of geometry.

In the research paper The Use of Variables in a Patterning Activity: Counting Dots, by Bożena Maj-Tatsis and Konstantinos Tatsis discuss secondary school students' use of variables when presented with some patterns of dots. The authors' aim was to establish a learning environment that would allow for fruitful and meaningful discussion in the classroom, and to examine what kind of shared meanings were raised among students with regard to the use of variables. Their analysis led the authors to different categories that reflected the different students' views on variables, of which greater importance was given to the examination of possibilities for a shift from a non-generalising to a generalising view of the variable. In this respect, it was observed that perceiving the variable as closely linked to the referred object (or to a part of it) could be viewed as a step towards perceiving the variable as a generalised number. Generally, we can conclude that, although the majority of the students overcame their difficulties with the notion of the variable, they still had problems with the notion of equivalence, which is another challenging and well-known area of research in the teaching and learning of mathematics.

The last paper relating to the topic of this special issue, Primary Teacher Students' Understanding of Fraction Representational Knowledge in Slovenia and Kosovo by Vida Manfreda Kolar, Tatjana Hodnik Čadež and Eda Vula, deals with primary teacher students' knowledge of fractions. Fractions is a very important topic in elementary mathematics because the idea of fractions is crucial for developing an understanding of other mathematical concepts, including algebra and probability. However, the understanding of fractions continues to be considered as a challenging topic for both learning and teaching. Several studies have found that teachers' knowledge directly influences the learning of fractions by students; therefore, the international education debate has stressed the importance of high-quality teaching as a central element in the quality of an education system. Considering results that deal with representations of fractions, we can conclude that primary teacher students from both countries performed better in solving the tasks from part to whole than from whole to part in each of the three modes of fraction representation (area, sets of objects and number line), and on average achieved better results in number line representations than in shape or set of object representations. The study confirmed the relevance of the question as to what good mathematical knowledge is, or what mathematical knowledge prospective teachers need for teaching basic concepts. Teachers should understand the subject in sufficient depth to be able 
to represent it appropriately and in multiple ways; therefore, teacher training programmes should provide more opportunities for them to improve their basic knowledge of fractions, as well of other relevant concepts.

The varia section includes two papers: Assessment of School Image by Ludvík Eger, Dana Egerová and Mária Pisoňová, and Croatian Preschool Teachers' Self-Perceived Competence in Managing the Challenging Behaviour of Children by Kathleen Beaudoin, Sanja Skočić Mihić and Darko Lončarić.

This issue of the CEPS Journal also includes two book reviews. Živa Kos reviews the book The Struggle for Teacher Education. International Perspectives on Governance and Reforms (London/New York: Bloomsbury Publishing, 2017) edited by Tom Are Trippestad, Anja Swennen and Tobias Werler, while Matjaž Poljanšek reviews the book The Future of School in Societies of Work without Work (Ljubljana: Faculty of Education, 2017), edited by Slavko Gaber and Veronika Tašner.

TATJANA HodnIK ČAdEŽ 